\title{
Vaccination Education Subordinated to Campaigning
}

\author{
Brian Martin (University of Wollongong)
}

\begin{abstract}
:
Proponents of vaccination would like to educate parents with the aim of getting them to agree with the dominant view. This creates a tension with an alternative goal of education, to encourage people to think for themselves. The challenge of learning about vaccination is increased by the public debate in which proponents and critics diverge dramatically and do not engage with each other's arguments.
\end{abstract}

Keywords:

authorities; education; polarisation; scientific controversies; vaccination

Should education about vaccination be geared to learning and accepting the views of authorities or should it be learning to think for oneself? There is a crucial tension between these two possibilities.

Vaccination is a public health measure designed to reduce disease. People are given vaccines, which are small amounts of infectious agents, modified so they cannot cause disease, with the aim of stimulating their immune systems and making them immune to full-blown disease. Vaccination is endorsed by nearly all government health authorities and researchers, and is commonly credited with greatly reducing mortality and morbidity from numerous infectious diseases such as polio, measles, pertussis and chickenpox (Ehreth, 2003; Offit \& Bell, 2003).

There have long been critics of vaccination. They argue that some people suffer adverse reactions and that there are benefits from natural immunity gained from having infectious diseases in childhood (Cernic, 2018; Habakus \& Holland, 2011). In addition, quite a few parents have reservations about vaccination. This is called 'vaccine hesitancy.' In 2019, the World Health Organisation declared vaccine hesitancy to be one of the top ten threats to public health. In this clash of viewpoints concerning a matter involving public health, what should be the role of education? On each side, some campaigners believe that individuals, if fully informed, would support their views. If so, then education should provide a solution: everyone, or nearly everyone, would arrive at the correct view, with campaigners on each side seeing their views as the correct ones.

Consider the proponents of vaccination. Some have advocated having respectful conversations with vaccinehesitant parents, who are encouraged to be aware of the implications of their decisions (Leask et al., 2012). This promises to influence some but not all such parents. Note that this approach is compatible with allowing or encouraging parents to think for themselves.

Asserting a View

On the other hand, some vaccination proponents, disturbed about parents who do not fully support the vaccination of their children, use other methods. One is to assume that vaccine-hesitant parents must have been misled by critics of vaccination. They typically say that people should trust doctors and health officials, thus relying on arguments from authority. Quite a few proponents have analysed websites with information critical of vaccination, under the assumption that this information is misleading parents (e.g., Kata, 2012). They seem to believe that people are susceptible to this 'dangerous' information: they cannot be trusted to examine information on both sides of the debate and hence decide to vaccinate their children according to the government schedule.

The next step is censorship. In Australia, pro-vaccination campaigners have attempted to silence critics, for example by discouraging venues from hosting talks by vaccine critics and discouraging mass media from reporting their views (Martin, 2018). There have been pressures put on platforms such as Amazon and Google to reduce the visibility of vaccinecritical views. Some critics have alleged that Google has manipulated searches to reduce the likelihood of coming across alternative health information (Ji, 2019). Censorship signals a distrust of people's judgement, specifically a fear that they will be unduly influenced by vaccine critics.

An alternative approach to information would be to encourage parents to understand the arguments better so they can resist the claims of vaccine critics: parents would thus be inoculated against the critics (Pfau et al., 2007). Following this approach would involve a careful analysis of the critics' 
arguments, showing their inadequacies. However, this is seldom done.

In the usual public debates over vaccination, neither side addresses all the other side's arguments. It is hard to find a single article by a vaccination supporter that summarises and addresses the critics' main arguments - and vice versa. Instead, each side typically presents its own strongest arguments and attacks the other side's weakest points (Gargiulo et al., 2020). For example, vaccination supporters hardly ever counter the long-standing observation that death rates from most infectious diseases dropped dramatically before the advent of mass vaccination, a decline usually attributed to improvements in hygiene, sanitation, diet and living standards (McKeown, 1979). Vaccine critics suggest that death rates might have continued declining even without vaccination. Instead, vaccination supporters repeatedly refer to a 1998 study by gastroenterologist Andrew Wakefield and twelve other scientists, saying it has been discredited or is fraudulent. However, concerns about vaccination do not derive only from this study (Largent, 2012, pp. 157-171). The result is that anyone wanting to understand the issues by studying the arguments will have a difficult time, because the two sides do not systematically engage with each other.

Another step by proponents is to use coercion against parents who do not follow all government recommendations. In the United States, for example, children must be fully vaccinated according to the government schedule in order to attend school. In most US states, there are three types of exemptions: medical, religious and philosophical. Some proponents argue that it should be difficult to obtain exemptions, as this will deter all but the most determined vaccine-hesitant parents. Legislators in several states have gone further, removing religious and philosophical exemptions. In terms of education, this sends the message that parents' personal views, no matter how well informed, are subordinated to government impositions.

In summary, the approaches used by quite a few vaccination proponents assume that the goal is support for or acquiescence to government schedules. They do not want people to think for themselves unless they arrive at the correct viewpoint. Associated with this view is an apparent lack of concern about the level of understanding by parents who accept vaccination schedules compared to alarm about those who don't.

\section{Polarisation}

The public vaccination debate is highly polarised: most participants line up on one side or the other, so there are few voices in between. Polarisation is quite common in public scientific controversies (Martin, 2014, pp. 26-28). In a polarised public controversy, partisans on each side collect any information they can use to support their positions. This means that deviating from the standard line potentially can be helpful to the other side: admitting a weakness in one's own position or a strength in the opponent's is then trumpeted by those on the other side. Because partisans use every available bit of evidence and argument to advance their favoured positions, anyone who adopts a middle or nonstandard position is shunned by one or both sides.

In the vaccination debate, it is rare to find someone who says, for example, that vaccination has limited benefits but nevertheless is still worthwhile or who says it has enormous benefits but nevertheless hesitancy should be respected and criticism should be welcomed. There are a few supporters of vaccination who encourage parents to consider modifying the schedules for vaccinating their children, for example spacing out some vaccines (Sears, 2013); such supporters may be criticised for deviating from the official line.

One result of polarisation is a lack of understanding of opponents, who may be seen as the enemy. Proponents of vaccination often label anyone who questions standard recommendations as an 'anti-vaxxer' which has become a term of dismissal or abuse. Although a few critics are opposed to all vaccines in all circumstances, there are far more who adopt a selective approach, choosing some but not all vaccines or spacing them out.

Another feature of polarisation is that new information seldom has any impact on the viewpoints of campaigners, which are highly entrenched. Furthermore, positions are not based solely on facts: values are crucially important. In the vaccination debate, proponents put a high value on the benefit to the community from high levels of vaccineinduced immunity, which means that individuals (in particular those with impaired immunity) benefit from nearly everyone else having immunity. On the other hand, critics put a high value on individual choice, especially in a situation in which some people suffer adverse reactions to vaccines. This difference in values cannot be bridged by introduction of more facts, which in turn suggests the importance of values education, which can clarify but not impose values. However, values education seems not to be encouraged by vaccination proponents, who have the numbers, resources and influence to encourage different sorts of education.

In summary, polarisation in public controversies inhibits learning because partisans give one-sided perspectives, middle voices are invisible and the emphasis on discrediting the other side means that learning about values is neglected.

\section{Authorities in Decline}

In many countries, there has been a long-term decline in public trust in authorities, including politicians, corporations, churches and the mass media (Botsman, 2017; Gurri, 2018; Nisbet, 1976). This decline has affected trust in science and medicine too (Shore, 2007). People are better educated, exposed to different points of view and, in particular, more aware of the shortcomings of authorities, for example political corruption, corporate malfeasance and paedophilia in the churches. Similarly, shortcomings in science and medicine - such as the misleading reassurances by scientific 
authorities about mad cow disease, and massive corruption payouts by pharmaceutical companies - have dented public confidence.

In the early decades of mass vaccination, there were relatively few vaccines. Scientists, such as the polio vaccine pioneers Jonas Salk and Albert Sabin, gifted their discoveries to the public. Beginning in the $1980 \mathrm{~s}$, things started to change. There were ever more vaccines in the government schedule (depending on the country; the US has had the most) and they were provided by pharmaceutical companies at a profit. These were the same pharmaceutical companies that have been accused of selling drugs they know are harmful, ghostwriting articles for medical journals, spending more on marketing than research, evergreening drugs to maximise profits, and lobbying to obtain economic advantage (Gøtzsche, 2013; Sismondo, 2018). If research results are suspect because of the influence of company sponsorship and marketing (Krimsky, 2019), why should members of the public trust them?

Many parents become concerned about vaccination because of declining trust in science and medicine, because they see their children receiving more vaccines than they did when they were children themselves, and perhaps most of all because of adverse reactions to vaccines. Some small percentage of children suffer illness, disability or death due to vaccinations. The figure is uncertain because most reactions are not reported to authorities. Indeed, many doctors vehemently reject any suggestion that illnesses could be due to vaccination, and this dogmatism contributes to vaccine hesitancy. If doctors and nurses are unwilling to consider the possibility of vaccine injuries, then parents will seek out those who will listen. This, arguably, provides continuing support for vaccine-critical groups - the very groups so widely condemned by pro-vaccination campaigners (Blume, 2017).

Given the ready availability of information about vaccination, it is to be expected that parents, especially those with the most education and who put the most effort into protecting their children, will continue to investigate for themselves and not rely entirely on authorities (Reich, 2016). Such parents are avid learners, but their learning takes place in difficult circumstances. The polarisation of the public vaccination debate means it is difficult to find trustworthy neutral sources of information.

\section{What to Do?}

Education about vaccination can be approached from either of two assumptions: that the goal is to inculcate beliefs considered correct, or that the goal is to encourage people to think for themselves. Pursuing both goals at once is not easy. For those whose goal is promoting correct beliefs and associated actions, current methods seem warranted, including censorship of dangerous ideas, one-sided presentation of information, denigration of opponents, assertion of authority and introduction of coercive policies.

For those whose goal is encouraging people to think for themselves, there are several challenges. The polarisation of the public debate is so extreme, indeed toxic, that it is not adequate to simply let people learn based on what is easiest to find in the public domain. Several types of interventions would help to enable learning. One is pointing to sources of information that address a range of arguments, not just the ones presented by partisans on one side or the other. Selflearners can assign themselves the task of seeking to map the evidence and arguments, pointing to assumptions and gaps. More ambitiously, they can try to write accounts that address perspectives that are submerged in the public debate. Finally, there is learning about values - including different ethical standpoints and different views about decision-making - and their role in the vaccination debate.

Judging by the longevity of several other public scientific controversies, it is unlikely that disagreements about vaccination will be resolved any time soon. This provides an educational opportunity: studying the debate and learning how participants use evidence and arguments provide an array of insights that can be applied to many of the other debates encountered in a technological world.

\section{References}

Blume, S. (2017). Immunization: How vaccines became controversial. Reaktion Books.

Botsman, R. (2017). Who can you trust? How technology brought us together - and why it could drive us apart. Penguin.

Cernic, M. (2018). Ideological constructs of vaccination. Vega Press.

Ehreth, J. (2003). The value of vaccination: A global perspective. Vaccine, 21(27-30), 4105-4117. https://doi.org/10.1016/S0264-410X(03)00377-3

Gargiulo, F., Cafiero, F., Guille-Escuret, P., Seror, V., \& Ward, J. K. (2020). Asymmetric participation of defenders and critics of vaccines to debates on French-speaking Twitter. Scientific Reports, 10(1), 6599. https://doi.org/10.1038/s41598$020-62880-5$

Gøtzsche, P. C. (2013). Deadly medicines and organised crime: How big pharma has corrupted healthcare. Radcliffe.

Gurri, M. (2018). The revolt of the public and the crisis of authority in the new millennium. Stripe Press. 
Habakus, L. K., \& Holland, M. (Eds.) (2011). Vaccine epidemic: How corporate greed, biased science, and coercive government threaten our human rights, our health, and our children. Skyhorse.

Ji, S. (2019, August 25). Google's digital book burn: Alternative medicine content now vanishingly rare, despite 1 billion health searches a day. https://www.greenmedinfo.com/blog/googles-digital-book-burn-alternative-medicine-content-nowvanishingly-rare-despi

Kata, A. (2012). Anti-vaccine activists, Web 2.0, and the postmodern paradigm - An overview of tactics and tropes used online by the anti-vaccination movement. Vaccine, 30(25), 3778-3789. https://doi.org/10.1016/j.vaccine.2011.11.112

Krimsky, S. (2019). Conflicts of interest in science: How corporate-funded academic research can threaten public health. Hot Books.

Largent, M. A. (2012) Vaccine: The debate in modern America. Johns Hopkins University Press.

Leask, J., Kinnersley, P., Jackson, C., Cheater, F., Bedford, H., \& Rowles, G. (2012). Communicating with parents about vaccination: A framework for health professionals. BMC Pediatrics, 12(1), 154. https://doi.org/10.1186/1471-2431$12-154$

Martin, B. (2014). The controversy manual. Irene Publishing.

Martin, B. (2018). Vaccination panic in Australia. Irene Publishing.

McKeown, T. (1979). The role of medicine: Dream, mirage or nemesis? Blackwell.

Nisbet, R. (1976). Twilight of authority. Heinemann.

Offit, P. A., \& Bell, L. M. (2003). Vaccines: What you should know (3rd ed.). John Wiley.

Pfau, M., Haigh, M. M., Sims, J., \& Wigley, S. (2007). The influence of corporate front-group stealth campaigns. Communication Research, 34(1), 73-99. https://doi.org/10.1177/0093650206296083

Reich, J. A. (2016). Calling the shots: Why parents reject vaccines. New York University Press.

Sears, R. W. (2011). The vaccine book: Making the right decision for your child (2nd ed.). Little, Brown.

Shore, D. A. (Ed.). (2007). The trust crisis in healthcare: Causes, consequences, and cures. Oxford University Press.

Sismondo, S. (2018). Ghost-managed medicine: Big pharma's invisible hands. Mattering Press.

\section{Recommended Citation}

Martin, B. (2020). Vaccination education subordinated to campaigning. On Education. Journal for Research and Debate, 3(8). https://doi.org/10.17899/on_ed.2020.8.4

About the Author

Brian Martin is emeritus professor of social sciences at the University of Wollongong, Australia. He is the author of 20 books and hundreds of articles on scientific controversies, dissent, nonviolent action, education and other topics. Web: https://www.bmartin.cc/ 